SHORT REPORT

\title{
Novel ENAM mutation responsible for autosomal recessive amelogenesis imperfecta and localised enamel defects
}

\author{
T C Hart, P S Hart, M C Gorry, M D Michalec, O H Ryu, C Uygur, D Ozdemir, S Firatli, G Aren, \\ E Firatli
}

J Med Genet 2003;40:900-906

The genetic basis of non-syndromic autosomal recessive forms of amelogenesis imperfecta (Al) is unknown. To evaluate five candidate genes for an aetiological role in Al. In this study 20 consanguineous families with $\mathrm{Al}$ were identified in whom probands suggested autosomal recessive transmission. Family members were genotyped for genetic markers spanning five candidate genes: $A M B N$ and ENAM (4q13.3), TUFT1 (1 q21), MMP20 (1 1q22.3-q23), and KLK4 (19q13). Genotype data were evaluated to identify homozygosity in affected individuals. Mutational analysis was by genomic sequencing. Homozygosity linkage studies were consistent for localisation of an Al locus in three families to the chromosome $4 q$ region containing the ENAM gene. ENAM sequence analysis in families identified a $2 \mathrm{bp}$ insertion mutation that introduced a premature stop codon in exon 10. All three probands were homozygous for the same g.13185_13186insAG mutation. These probands presented with a generalised hypoplastic Al phenotype and a class II openbite malocclusion. All heterozygous carriers of the g.13185_13186insAG mutation had localised hypoplastic enamel pitting defects, but none had Al or openbite. The phenotype associated with the g.13185_13186insAG ENAM mutation is dose dependent such that ARAl with openbite malocclusion segregates as a recessive trait, and enamel pitting as a dominant trait.

$\mathrm{T}$ he amelogenesis imperfectas (AI) are a clinically and aetiologically heterogeneous group of heritable disorders characterised by qualitative or quantitative anomalies of enamel development. While syndromic and non-syndromic forms of AI are reported, non-syndromic forms are the most prevalent. ${ }^{12}$ Although multiple classifications systems have been proposed for this condition, our current understanding of its aetiology does not allow the development of a robust nosology to account for the phenotypic variability observed. ${ }^{3-5}$

Both $\mathrm{X}$ linked and autosomal transmission of nonsyndromic forms of AI are well documented. ${ }^{6-9}$ Most forms of $\mathrm{X}$ linked AI are caused by mutation of the amelogenin gene, $\left(A M E L X^{10}\right) .{ }^{11}$ The most common autosomal forms of $\mathrm{AI}$ show dominant transmission. Genetic linkage studies indicate that at least two distinct autosomal loci are responsible for dominant forms of AI, with some cases caused by enamelin $\left(E N A M^{12}\right)$ gene mutations. ${ }^{5}{ }^{13-17}$ Identification of genes responsible for $\mathrm{X}$ linked and autosomal dominant forms of AI has contributed to a better understanding of the disease pathogenesis, and in some cases, genotype-phenotype correlations are emerging. ${ }^{18}$

In contrast to the successes in identifying the genetic basis of autosomal dominant and $\mathrm{X}$ linked forms of AI, genetic studies have not identified or localised genetic loci for nonsyndromic forms of autosomal recessive AI (ARAI). Based on biological function and tissue expression, five candidate genes have been proposed for autosomal forms of AI, including ameloblastin $(A M B N)$, enamelin $(E N A M)$, tuftelin (TUFT1), enamelysin (MMP20), and kallikrein 4 (KLK4). ${ }^{14}{ }^{19-24}$ To evaluate support for or against linkage of these candidate loci with non-syndromic ARAI, we undertook homozygosity linkage studies in 20 nuclear families. In this paper we report identification of a novel ENAM mutation in probands from three families. Homozygous carriers of this novel mutation show AI and openbite malocclusion, while heterozygous carriers have only a mild localised enamel pitting phenotype.

\section{METHODS \\ Pedigrees and diagnosis}

Affected individuals were identified by proband ascertainment from dental clinics at the School of Dentistry, University of Istanbul, Istanbul, Turkey in accordance with institutional review board approval from the University of Istanbul and the University of Pittsburgh. Available family members had an oral examination and dental radiographs to characterise the AI phenotype when present. The presence of the disorder was established by generalised yellow-brown discolouration of the teeth, decreased enamel mineralisation, and pathological loss of enamel. Using modifications of clinical criteria previously proposed by Witkop, ${ }^{1}$ affected individuals were classified into one of four groups: hypoplastic; hypomaturation; hypocalcified; and hypomaturation/ hypoplasia with taurodontism. ${ }^{3}$

In addition to oral examinations, complete medical histories were taken to identify any additional clinical findings that would be consistent with syndromic conditions. Individuals with syndromic presentations of $\mathrm{AI}$ were excluded from the analyses.

Cephalometric and panoramic radiographs, photographic records, and dental casts were obtained to characterise the presence of skeletal openbite malocclusion in individuals with clinically evident openbite. Standard lateral cephalography was undertaken using a Cranex-3+Ceph at $10 \mathrm{~mA}$ and $81 \mathrm{kV}$ (Cranex Co, Helsinki, Finland). Conventional cephalometric landmarks were identified and 15 angular and 15 linear measurements were made. ${ }^{25}$ Negative values for the recordings of overbite represent a dentoalveolar anterior openbite. The facial ratio expressed by the relation between upper face height and total face height was calculated from

\footnotetext{
Abbreviations: ADAl, autosomal dominant amelogenesis imperfecta; $\mathrm{Al}$, amelogenesis imperfecta; ARAl, autosomal recessive amelogenesis imperfecta; LHED, localised hypoplastic enamel defects; SNP, single
} nucleotide polymorphism; STRP, short tandem repeat polymorphism 
the formula $\mathrm{N}-\mathrm{ANS} / \mathrm{N}-\mathrm{Me} \times 100$, where $\mathrm{N}-\mathrm{ANS}=$ mid facial height and $\mathrm{N}-\mathrm{Me}=$ total face height.

\section{Molecular genetic analyses \\ DNA marker analysis}

Genomic DNA was isolated from whole blood by standard techniques using the QIAamp blood kit (Qiagen). Family members were genotyped for STRP (short tandem repeat polymorphism) genetic markers spanning the five autosomal candidate loci, selected on the basis of their role in enamel development. Three gene loci (TUFT1, MMP20, and KLK4) were genotyped using previously described STRPs. ${ }^{17}$ Although the $A M B L$ and ENAM loci have been mapped to chromosome $4 \mathrm{q} 2 \mathrm{l}$, their precise location and position relative to each other has only recently been determined ${ }^{17}$ Three novel STRP loci spanning the $A M B L$ and ENAM loci were identified using the tandem repeats finder program. ${ }^{26}$ Oligonucleotide primers used to amplify these loci were: 719MI6: F 5' - CCATTAGAGCTATTTCAGATA-3'; R 5'- CACAAAGCCAGAGAA ACATTA -3'; AMB: F 5'-GATTCAGCATCAACTTCCACAGAG-3': R 5'-CCAGCCTGAGCTTGTCTTAAAGAT-3'; and 92H22: F 5'CTCGCTTTGGGTTTCTCTGATGTT-3', R 5'- CTGGCA ATGTGGGCTGRCTCTACA- $3^{\prime}$.

Marker loci were amplified by polymerase chain reaction, using fluorescence labelled primers, permitting genotyping by conventional methods. ${ }^{27}$ Single nucleotide polymorphisms (SNPs) were identified and localised within the $A M B N-E N A M$ region of chromosome $4 \mathrm{q} 13$, based on the alignment of candidate SNPs with the physical map developed in our laboratory. ${ }^{17}$ SNPs were identified on the basis of sequence data from public and propriety databases (ABI , http:// www.appliedbiosystems.com/apps/) and the NCBI SNP database (http://www.ncbi.nlm.nih.gov/). SNP assays were obtained from Applied Biosystems (ABI) and were genotyped using an ABI 7900HT (Applied Biosystems). Allele calling was done using the 7900HT software.

\section{ENAM mutation analysis}

The exons and exon/intron boundaries of the enamelin gene were amplified as previously described. ${ }^{5}$ Extracted amplicons were sequenced in both directions using $\mathrm{ABI}$ Big Dye terminator chemistry and an ABI 3700 DNA analyser (Applied Biosystems). Groups of 50 unaffected Turkish control individuals (100 alleles) and 50 unaffected control individuals (100 chromosomes) of European and African descent were also sequenced.

\section{RESULTS}

\section{Clinical findings}

Identification of probands with AI resulted in the ascertainment of 20 nuclear families with a history of parental consanguinity. The distribution of probands into AI subtypes was: hypoplastic (10 families); hypomaturation (four families); hypocalcified (one family); and hypomaturation/ hypoplasia with taurodontism (five families). We studied 106 family members from these 20 families (20 probands, 40 parents, six affected siblings, 24 unaffected siblings, and 16 cousins, aunts, uncles, and grandparents).

\section{Genotyping results}

Genotype data were not consistent with homozygosity for genetic marker loci spanning the chromosome lq21 (TUFT1), 1 lq22.3-q23 (MMP20), and 19q13.3-q13.4 (KLK4) candidate intervals in the affected probands from any of the 20 families. Genotyping results indicated that three probands (family 2, II-4; family 7, VI-1; family 12, IV-1) were homozygous for STRP markers from the chromosome 4q (AMBN-ENAM) candidate interval (fig 1). Genotyping for eight SNP markers spanning a genetic interval of $<50 \mathrm{~kb}$ containing the ENAM
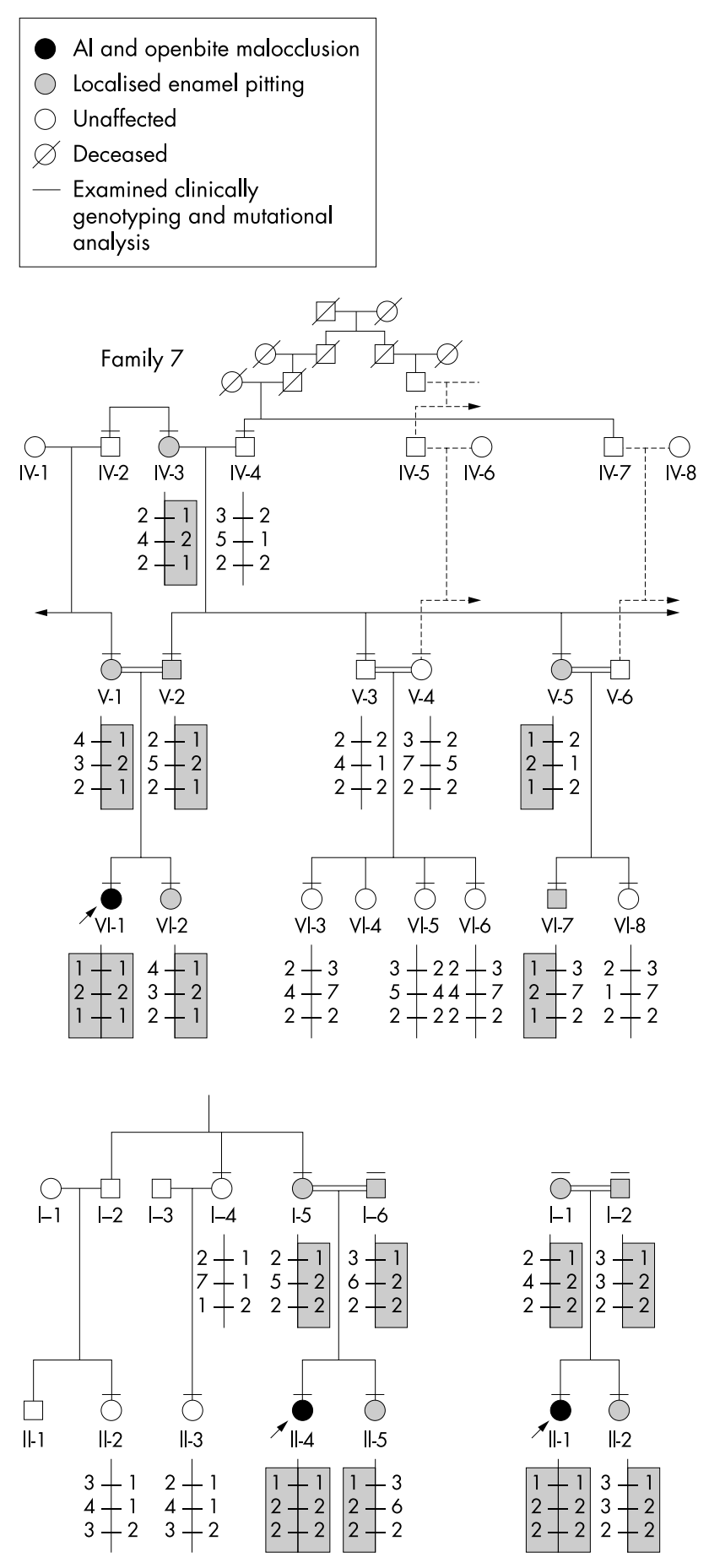

Family 2

Family 12

Figure 1 Pedigrees of three families segregating amelogenesis imperfecta (AI) and openbite malocclusion as an autosomal recessive trait. Localised enamel pitting also segregates as a dominant trait in all three families. Individuals clinically examined and sampled for genetic studies are indicated by solid lines over respective individuals. Genotype data for genetic markers spanning the chromosome $4 q 13.3$ candidate region are indicated below each individual. Haplotypes segregating with the $\mathrm{Al}$ /openbite and enamel pitting phenotypes are shown in the shaded box. Marker/loci order and intermarker distance $(\mathrm{kb})$ are \{719M16-(265 kb)-AMB-(0.3 kb)-AMBL locus-(7.4 kb)-ENAM locus(265 kb)-92 $\mathrm{H} 22\}$.

locus indicated all three probands were homozygous for an identical haplotype, refining the candidate interval to the 
ENAM locus. Genotype data from none of the other 17 families were supportive of homozygosity of genetic marker loci spanning the chromosome 4q13.3 candidate interval in the affected probands.

\section{ENAM mutation analysis}

Sequencing of the enamelin gene showed that the affected probands from families 2, 7, and 12 were all homozygous for a 2 bp insertion mutation in exon 10 of ENAM (fig 2). The resultant frameshift codes for 26 novel amino acids and introduces a premature termination at codon 448 .

According to the nomenclature guidelines for ENAM mutations, ${ }^{5}$ this mutation is designated as g.13185_13186insAG (c.1258_1259insAG; p.P422fsX448). All six parents and three siblings of these probands were heterozygous carriers of the g.13185 13186insAG mutation. Of 12 additional family members available for study, three were carriers of the g.13185_13186insAG mutation. Sequence analysis of the ENAM exon 10 did not identify this g.13185 13186insAG mutation in any of 50 unrelated unaffected Turkish controls (100 alleles) or 50 unrelated unaffected controls of European and African descent (100 alleles). Sequence analysis of all coding regions and intronexon boundaries of the ENAM gene undertaken for the 17 probands from other families which were not consistent for linkage to this candidate region did not identify the g.13185_13186insAG mutation or any other ENAM mutation.

\section{Genotype-phenotype correlations}

Clinical findings in the three probands homozygous for the g.13185 13186insAG mutation were consistent with a severe generalised AI phenotype that appeared both clinically hypoplastic and radiographically undermineralised (fig 3). Taurodontism was not present in any individuals, and no anomalies of dental pulp or root structures were radiographically evident (fig $3 \mathrm{C}$ ). In addition to $\mathrm{AI}$, these three probands were also noted to have a clinically evident openbite type malocclusion (fig 3B). Openbite diagnosis was confirmed by cephalometric analysis (table 1). All three probands (family 2, II-4; family 7, VI-1; family 12, II-1) had a retrognathic mandibular position ( SNB angles $70^{\circ}-73^{\circ}$ ), class II malocclusion (ANB angles $5^{\circ}$ to $7.5^{\circ}$ ), and vertical relations (indicated by the sum of the saddle, articular, and gonial angles) were greater than the normal values. In all three probands, $\mathrm{Y}$ axis angles, FMA angles, and the angles between maxillary and mandibular planes were greater than the normal values. The Jarabak ratio indicated that these three probands were in high angle pattern with anterior openbite. Thus all three probands showed AI and cephalometric

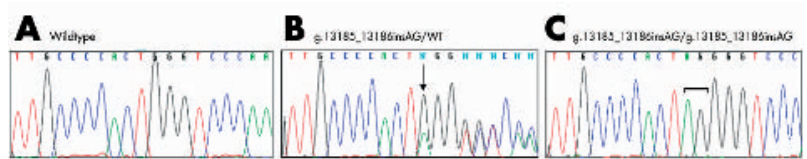

D

WT: . PIGPKPGPW RHEKIQNPKE KPIGP . LQAX

Mutant: ...PLGVPNLALL FAMKKSKIQR RSPWVQKNKX

Figure 2 Mutational analysis of ENAM. (A) Wild-type sequence. (B) Sequence from carrier (family 7, V-2) showing frameshift (arrow). (C) Sequence from affected individual (family $7, \mathrm{VI}-1$ ) demonstrating the insertion of an AG (g.13185 13186insAG). (D) Predicted effect of mutation on the enamelin protein. The top is a portion of the 1142 amino acid wild-type protein (WT). Below is the consequence of the frameshift. The chimeric protein is predicted to have 421 amino acids of the wildtype protein followed by 26 novel amino acids, for a total of 447 amino acids.
A
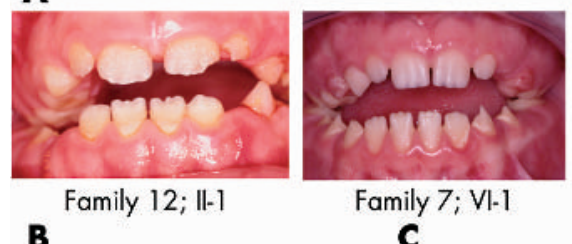

Family 7 ; VI-1

c

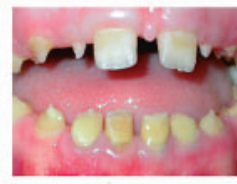

Family $2 ; \| 1-4$
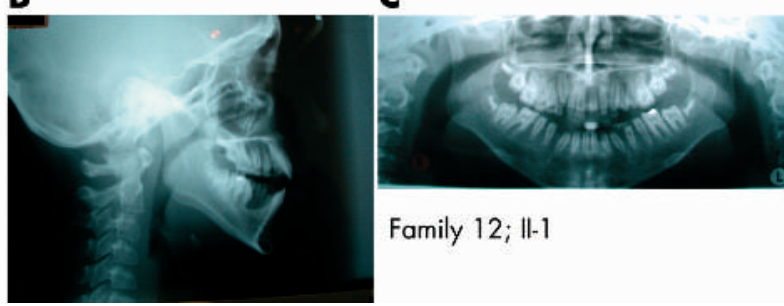

Family $12 ; \| 1$

Figure 3 (A) Photographs of probands from families shown in fig 1. All three probands show generalised hypoplastic enamel characteristic of hypoplastic amelogenesis imperfecta. The enamel has fractured from several teeth in the family 12 proband. The posterior teeth are in occlusion in all cases, and the clinically evident anterior openbite is seen in all three probands. (B) Lateral cephalometric radiograph of proband II-1 from family 12. Anterior openbite is evident. (C) Panorex showing a general reduction in enamel thickness and lack of demarcation between enamel and dentin consistent with reduced enamel mineralisation. Root anatomy is normal and taurodontism is not present.

features of skeletal openbite. No other family members had clinical openbite.

Clinical and radiographic examination of teeth from relatives of the affected probands showed that none had a clinical diagnosis of AI and none presented with a clinical openbite malocclusion. However, all the probands' parents, three siblings, and three of their relatives were found to have localised circumscribed discrete areas of enamel hypoplasia consistent with a clinical diagnosis of enamel pitting (fig 4). All individuals with these localised enamel defects were heterozygous carriers of the ENAM mutation (g.13185 13186insAG mutation/wild-type). Localised circumscribed enamel defects were found on the buccal surfaces of the anterior teeth, and on the occlusal surfaces and cusps of the canines, premolars, and molars (fig 4). Local enamel defects were found only in family members who were heterozygous for the ENAM mutation.

\section{DISCUSSION}

In these analyses, genetic linkage studies were consistent for localisation of an ARAI locus to the AI candidate region of chromosome 4q13.3 in three of the 20 families studied. Genomic DNA sequence analysis of the three affected probands identified a two base pair insertion mutation in exon 10 of the ENAM gene. The murine ENAM gene has 10 exons. The human ENAM gene has been described as having nine exons. The human cDNA lacked the sequence corresponding to murine exon 2. However, the human ENAM gene homologous sequence is flanked by appropriate splicing junctions, raising the possibility that alternative splicing of this exon occurs. An analogous situation is seen with amelogenin, where $99 \%$ of the transcripts lack exon 4 . Table 2 presents the known ENAM mutations in the more robust standardised ENAM nomenclature, ${ }^{5}$ to make it easy for readers to compare mutations from various studies.

On the basis of nomenclature guidelines, ${ }^{528}$ we have designated the insertion between nucleotides 13185 and 13186 in the genomic sequence (g.13185_13186insAG) and between nucleotides 1258 and 1259 in the ENAM cDNA sequence (c.1258_1259insAG). The codon for amino acid L420 is changed from CTG to CTA, which still encodes 
Table 1 Cephalometric measurements of patients with amelogenesis imperfecta

\begin{tabular}{|c|c|c|c|c|}
\hline & Normal values* & Family 7 , VI-1 & Family 12 , II-1 & Family 2, II-4 \\
\hline $\mathrm{SN}-\mathrm{Go}-\mathrm{Me}\left({ }^{\circ}\right)$ & $32(5)$ & 48 & 44 & 56 \\
\hline Saddle angle $\left({ }^{\circ}\right)$ & $123(5)$ & 123 & 126 & 125 \\
\hline Articular angle ( $\left.{ }^{\circ}\right)$ & $143(6)$ & 155 & 141.5 & 146 \\
\hline$\sum\left(^{\circ}\right)$ & 396 (3) & 408 & 402.5 & 416.5 \\
\hline Jarabak ratio (\%) & $59-62$ & 53.6 & 56.9 & 51 \\
\hline $\mathrm{UFH} / \mathrm{TFH} \times 100$ & 43.84 & 45 & 43 & 42 \\
\hline$Y$ axis angle $\left({ }^{\circ}\right)$ & 59.4 & 69 & 66.5 & 74.5 \\
\hline FMA $\left({ }^{\circ}\right)$ & 25 & 35 & 36.5 & 50 \\
\hline ANS-PNS/Go-Me ( $\left.{ }^{\circ}\right)$ & 25 & 36 & 35 & 45 \\
\hline SNA $\left({ }^{\circ}\right)$ & $82(2)$ & 80 & 75 & 77.5 \\
\hline SNB ( $\left.0^{\circ}\right)$ & 80 (2) & 73 & 70 & 70 \\
\hline ANB $\left(1^{\circ}\right)$ & $2-4$ & 7 & 5 & 7.5 \\
\hline $\mathrm{S}-\mathrm{N}(\mathrm{mm})$ & $77(4)$ & 64 & 69 & 68 \\
\hline ANS-PNS $(\mathrm{mm})$ & $57(4)$ & 47 & 45 & 52 \\
\hline $\mathrm{Go}-\mathrm{Me}(\mathrm{mm})$ & $74(6)$ & 69 & 61 & 70 \\
\hline $\mathrm{N}-\mathrm{Me}(\mathrm{mm})$ & $113(0.65)$ & 117 & 112 & 131 \\
\hline Overiet $(\mathrm{mm})$ & 2 & 2 & 2,5 & 8 \\
\hline Overbite $(\mathrm{mm})$ & 2 & -3 & -5 & -10 \\
\hline
\end{tabular}

*Values are mean (SD), range, or maximum.

ANS-PNS, length of maxillary base; articular angle, angle between sella, articulare, and gonion points; FMA angle between Frankfort horizontal plane and mandibular plane; Go-Me, length of mandible; Jarabak ratio, ratio of posterior (sella to gonion) to anterior facial height (nasion to menton); $\mathrm{N}-\mathrm{Me}$, total face height; overbite, distance between the incisal edge of the maxillary central incisor to the incisal edge of the lower central incisor perpendicular to the occlusal plane; overjet, distance between the incisal edge of the maxillary central incisor to the most labial point on the crown of the mandibular central incisor; sandle angle, angle between nasion, sella, and articulare points; SNA, angle between sella turcica, nasion and A points (position of the mandible to skull base); $\mathrm{SNB}$, angle between $\mathrm{A}$, nasion, and $\mathrm{B}$ points (relation of maxilla and mandible to each other); $\mathrm{S}-\mathrm{N}$, length of anterior cranial base (the measurements between sella turcica and nasion points); SN-GoMe: angle between mandibular plane and skull base; UFH/TFH $\times 100$, ratio of upper facial height (N-NANS) to total facial height (N$\mathrm{Me}) \times 100$; $Y$ axis angle, $Y$ axis to Frankfort horizontal plane (the lower angle between $Y$ axis (a line from Sella turcica to gnathion) and Frankfort horizontal plane running through the right and the left orbitale points); $\Sigma$, the sum of saddle, articulare, and gonial angles (it must be $396^{\circ}$ ).

leucine, but the additional nucleotides produce a frameshift and an early termination of the protein. The chimeric 447amino acid protein consists of $421 \mathrm{~N}$-terminal amino acids followed by 26 replaced amino acids and a premature stop codon at codon 448 (p.P422fsX448). This mutation dramatically alters the protein cleavage products of the enamelin gene. The g.13185_13186insAG ENAM mutation was not present in any of 200 control chromosomes from unrelated individuals without enamel defects, suggesting this allele is not a common variant of the enamelin gene. The segregation of this mutation in three families with enamel anomalies, and the lack of this mutation in 200 control chromosomes from unaffected individuals, supports a causal role for this
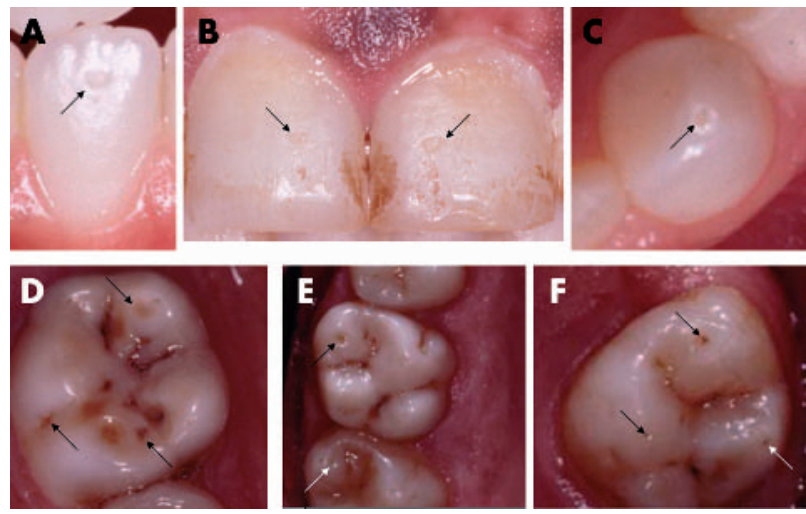

Figure 4 Local circumscribed enamel pitting present in heterozygous carriers of the ENAM g.13185_13186insAG mutation. (A) Enamel pit present on buccal surface of mandibular incisor (VI-2, family 7). (B) Enamel pit present on buccal surfaces of maxillary incisors in father (V-2) of family 7 proband (VI-1). (C) Enamel pit on mandibular cuspid (family 2, I-5). Multiple enamel pits present on occlusal surface of mandibular molar (D) (family 12, I-1), and on maxillary molars, individual I-1, family 12 (E) and individual V-2, family 7 (F). mutation with enamel defects. Based on clinical and laboratory findings, we propose that the g.13185_13186insAG ENAM mutation segregates localised hypoplastic enamel pitting as a dominant trait, and hypoplastic AI with a skeletal class II openbite malocclusion as a recessive trait.

Demonstration of an ENAM mutation causing ARAI provides an explanation for the often reported sporadic occurrence of this condition and indicates that such cases are compatible with autosomal recessive transmission of an underlying gene defect. The current findings also show genetic heterogeneity for autosomal recessive AI. The generality of ENAM mutations in ARAI is unknown, yet the fact that no other ENAM mutations were found in the remaining 17 probands, and the lack of support for allelic homozygosity for markers throughout this genetic interval in these probands, suggests that other autosomal loci are responsible for non-syndromic ARAI. While the three families with the g.13185_13186insAG ENAM mutation were not known to be related, the common haplotype shared by all three suggests the mutation has been inherited "identical by descent" from a common ancestor.

Clinical findings associated with the g.13185_13186insAG ENAM mutation are dose dependent. Dose dependent increases in phenotype severity are known to be associated with certain mutations (for example, for familial hypercholesterolaemia associated with mutations in the low density lipoprotein receptor gene $\mathrm{e}^{29}{ }^{30}$ ). The interesting clinical correlate of the ENAM g.13185_13186insAG mutation is that the mild enamel pitting phenotype would not be considered a mild form of AI. Enamel pitting is a recognised clinical phenotype, but the mild form seen in carriers of the g.13185_13186insAG mutation has not previously been associated with AI. The dose dependent clinical findings related to the g.13185_13186insAG mutation have implications for understanding the role of enamelin in enamel development and also for AI nosology. 
Table 2 Mutations described in ENAM

\begin{tabular}{|c|c|c|c|c|c|c|}
\hline Genomic DNA* & cDNA $\dagger$ & Location & Protein $\ddagger$ & Phenotype & Inheritance & Reference \\
\hline $\begin{array}{l}\text { g. } 2382 A>T \\
\text { g.6395G }>A \\
\text { g.8344delG } \\
\text { g. } 13185 \text { 13186insAG }\end{array}$ & $\begin{array}{l}\text { c. } 157 A>T \\
\text { IVS8+1G }>\text { A; c. } 534+1 G>A \\
\text { IVS9+1delG; c. } 588+1 \text { delG } \\
\text { c. } 1258 \text { 1259insAG }\end{array}$ & $\begin{array}{l}\text { Exon } 5 \\
\text { Intron } 8 \\
\text { Intron } 9 \\
\text { Exon } 10\end{array}$ & $\begin{array}{l}\text { p.K53X } \\
\text { p.A158_Q178 } \\
\text { p.N197fsX277 } \\
\text { p.P422fs X448 }\end{array}$ & $\begin{array}{l}\text { Local hypoplastic } \\
\text { Smooth hypoplastic } \\
\text { Smooth hypoplastic } \\
\text { Hypoplastic }\end{array}$ & $\begin{array}{l}A D \\
A D \\
A D \\
A R\end{array}$ & $\begin{array}{l}\text { Mardh }^{16} \\
\text { Rajpar }^{14} \\
\text { Kida }^{15} \text {; Hart } \\
\text { This report }\end{array}$ \\
\hline
\end{tabular}

*Reference sequence for GenBank accession No AY167999; the A of the initiator ATG is taken as +1 .

†Reference sequence for GenBank accession No AFa25373; the A of the initiator ATG is taken as +1 .

IInitiator methionine as the +1 position.

$A D$, autosomal dominant; $A R$, autosomal recessive.

The enamel specific protein, enamelin, is highly conserved among animals and comprises approximately $5-10 \%$ of enamel proteins. ${ }^{31}$ The human enamelin signal peptide has 39 amino acids and the secretory protein has $1103 .{ }^{23}$ Enamelin is secreted as a precursor that undergoes proteolytic processing to yield several functional cleavage products. Enamelin cleavage products have been extensively studied in human and porcine models. ${ }^{32}{ }^{33}$ Results of immunolocalisation studies suggest that the 142 and $89 \mathrm{kDa}$ enamelin products are found in newly formed enamel, whereas the 32 $\mathrm{kDa}$ enamelin and low molecular weight proteins are detected in the inner enamel layer. ${ }^{34}$ Further processing of the $142 \mathrm{kDa}$ enamelin produces an $89 \mathrm{kDa}$ and a $34 \mathrm{kDa}$ cleavage product. Subsequent cleavage of the $89 \mathrm{kDa}$ enamelin produces a $25 \mathrm{kDa}$ species. The various enamelin cleavage products may have different roles in enamel development, as evidenced by their differential compartmentalisation in developing enamel. ${ }^{35}$ Among the cleavage products, the structure of the $32 \mathrm{kDa}$ enamelin is well characterised and is reported to be N-linked glycosylated at three sites and phosphorylated at two serines. ${ }^{36}$ It is particularly stable, absorbs strongly onto apatite crystals in developing enamel, and accumulates to comprise about $1 \%$ of the total enamel protein. ${ }^{37}$ Glycosylation generally increases the acidity of a protein, which could act to increase its affinity for hydroxyapatite. The interaction of enamelin and amelogenin may contribute to the development of a well organised enamel structure by supporting a framework of prism rods. ${ }^{38}$ A recent report that amelogenin binds to $\mathrm{N}$-acetylglucosamine illustrates the potential importance of such proteinprotein interactions in enamel development. ${ }^{39}$ Interestingly, a single amino acid mutation in amelogenin is sufficient to destroy its binding affinity to $\mathrm{N}$-acetylglucosamine and cause $\mathrm{X}$ linked AI. ${ }^{40}$

Our current findings extend to four the number of enamelin gene mutations reported to be responsible for AI (table 2). The three enamelin gene mutations previously reported all cause AI that segregates as an autosomal dominant trait. These three mutations occur 5' from the g.13185_13186insAG mutation. The local hypoplastic form of autosomal dominant AI (ADAI) found with the previously reported g.2382A $>\mathrm{T}$ (p.K53X) mutation most probably results from haploinsufficiency for the various enamelin cleavage products $(32 \mathrm{kDa}, 25 \mathrm{kDa}$, and $34 \mathrm{kDa}) .{ }^{16}$ The other two previously reported ENAM mutations are believed to affect the $32 \mathrm{kDa}$ cleavage product, resulting in a generalised form of smooth hypoplastic AI. ${ }^{5}{ }^{14}{ }^{15}$ In these later cases, there is an overall reduction in the amount of enamel produced. Whether the g.6395G $>\mathrm{A}$ and g.8344delG mutations act through haploinsufficiency or a dominant negative effect is unknown, but both affect the $32 \mathrm{kDa}$ cleavage product, and the associated AI phenotype segregates as a dominant trait. In contrast, the currently reported g.13185_13186insAG mutation occurs downstream of the $32 \mathrm{kDa}$ cleavage site and is predicted to result in a truncated protein that is 695 amino acids shorter than the wild-type protein of 1142 amino acids. Thus carriers for the mutation would produce normal amounts of the $32 \mathrm{kDa}$ enamelin but only $50 \%$ of the $25 \mathrm{kDa}$ and $34 \mathrm{kDa}$ cleavage products.

In contrast to the dominant transmission of the AI clinical phenotypes reported for the previous ENAM mutations, the g.13185_13186insAG mutation does not cause AI when present in the heterozygous state. Teeth of carriers of this mutation have only a variable number of localised circumscribed areas of hypoplastic enamel that appear as pits approximately $1-2 \mathrm{~mm}$ in diameter and depth. The colour of the enamel in these defective pits, as well as in areas of normal enamel thickness, is normal. Yet the severe generalised AI phenotype observed in individuals homozygous for this mutation suggests that the $25 \mathrm{kDa}$ and $34 \mathrm{kDa}$ enamelins are crucial for normal enamel development.

Localised circumscribed hypoplastic enamel defects (LHED) that appear as enamel pitting were present in all heterozygous carriers of the g.13185_13186insAG ENAM mutation. This enamel pitting was present on the labial surfaces of the incisors, and more commonly on the labial surfaces of the canines, as well as on the occlusal surfaces of the canines and posterior teeth (fig 4). Similar areas of enamel hypoplasia were not present in family members without the mutation. This is the first identification of a specific gene mutation associated with this limited disturbance of enamel development. The generality of this specific gene mutation for such hypoplastic enamel defects is unknown, but raises the possibility that other allelic ENAM mutations, as well as mutations of different enamel related genes, may cause LHED. This finding has implications for the identification of aetiological factors associated with local enamel defects.

As enamel defects provide a permanent record of exposure to factors that may interfere with normal enamel development, localised defects have been studied in a variety of human and primate populations. LHED have been used as an indicator of lifestyle and stress in human and ape populations by anthropologists. ${ }^{41-44}$ While the patterns in LHPC expression are similar in humans and apes, the prevalence of such defects varies with different study populations. The prevalence of discrete areas of defective enamel formation varies in prehistoric populations (rare in Neanderthal, $>40 \%$ in upper paleolithic and neolithic) and current human populations $(<1 \%$ to $>56 \%){ }^{45-49}$ The prevalence of enamel defects also varies among apes, from $0.0 \%$ in gibbons to $61.5 \%$ in bonobos and $>85 \%$ in orangutans and gorillas. ${ }^{50-52}$ While diverse aetiological factors including diet, stress, fever, injury, infection, and genetics have been proposed for localised enamel defects, most emphasis has been placed on nongenetic factors. The current findings suggest that mutations in genes important in amelogenesis may play a significant role in the aetiology of local enamel hypoplasia, suggesting that genetic factors are more important in LHED aetiology than previously believed. Recessive mutations in both human and ape populations could account for the variance in enamel defect prevalence reported. 
An anterior openbite malocclusion, generally considered to be of skeletal origin, is a frequent associated finding in AI. ${ }^{53-60}$ In the current study, individuals homozygous for the g.13185_13186insAG mutation were noted to have an anterior openbite malocclusion as well as AI. Skeletal anterior openbite arises because of disharmony in the vertical relation between the maxillary and mandibular bases, characterised by increased gonial and mandibular plane angles. Results of lateral cephalometric analysis were consistent with a class II malocclusion in the three probands homozygous for the g.13185_13186insAG mutation (table 1). This malocclusion was not present in any other family members. While some believe that the coexistence of AI and openbite malocclusion may be attributed to pleiotropic action of the AI gene(s) influencing the growth of the craniofacial skeleton, ${ }^{55} 6162$ others contend that openbite reflects the influence of modifying genes or environmental factors. ${ }^{58}$ Witkop argued that true AI involved only enamel defects, attributing the frequent association of anterior openbite with AI to a locally acting mechanism whereby thermally sensitive teeth lead to a tongue thrusting habit which acts as a local impediment to alveolar growth, producing anterior openbite. ${ }^{63}{ }^{64}$ Given AI is rare and anterior openbite is uncommon, occurring in around $2 \%$ of teenagers, ${ }^{65}$ the frequent occurrence of both conditions appears more than coincidental. The relation of the underlying gene of major effect mutation to the observed malocclusion in AI is unclear, yet the association of openbite malocclusion with a large number of AI cases suggests an aetiological association. In contrast to bones in the rest of the body that are derived from the mesoderm of the primitive streak, in the craniofacial complex the neural crest cells originating from the ectoderm give rise to the ectomesenchyme, from which much of the skull is formed..$^{55}$

Various different classification systems have been proposed for AI, with most based on the clinical phenotype of teeth and the mode of Mendelian transmission. ${ }^{134}$ However, with more than 14 clinical types of non-syndromic AI, the clinical variability seen within some families, and the variable clinical findings involving AI and openbite malocclusion, classifications based on clinical findings in AI can be extremely cumbersome. ${ }^{351566} 67$ Identification of additional gene loci responsible for AI should improve our understanding of the underlying physiological disturbances, and help to explain the phenotypic variability. The emerging genotype-phenotype correlations for ENAM mutations indicate that a fundamental understanding of how each specific gene mutation affects enamel development will be necessary to provide the appropriate information to develop a robust nosology with clinical value. ${ }^{68}$

\section{ACKNOWLEDGEMENTS}

We thank the families who generously participated in these studies and acknowledge support from the National Institutes of Dental and Craniofacial Research R-01DE12920

\section{Authors' affiliations}

T C Hart, Department of Oral Medicine and Pathology, School of Dental Medicine and Department of Human Genetics, School of Public Health, University of Pittsburgh, Pittsburgh, Pennsylvania, USA

P S Hart, Department of Human Genetics, School of Public Health, University of Pittsburgh

M C Gorry, Department of Oral Medicine and Pathology, School of Dental Medicine, University of Pittsburgh

M D Michalec, Department of Human Genetics, School of Public Health, University of Pittsburgh

O H Ryu, Department of Oral Medicine and Pathology, School of Dental Medicine, University of Pittsburgh

C Uygur, Department of Periodontology, School of Dentistry, University of Istanbul, Istanbul, Turkey

D Ozdemir, Department of Pedodontics, School of Dentistry, University of Istanbul

S Firatli, Department of Orthodontics, School of Dentistry, University of Istanbul

G Aren, Department of Pedodontics, School of Dentistry, University of Istanbul

E Firatli, Department of Periodontology, School of Dentistry, University of Istanbul

Correspondence to: Dr Thomas C Hart, National Institutes of Health, NIDCR, Building 10, Room 1N-117, 10 Center Drive, Bethesda, MD 20892, USA; thart@mail.nih.gov

Received 30 May 2003

Accepted 17 July 2003

\section{REFERENCES}

1 Witkop CJJ. Amelogenesis imperfecta, dentinogenesis imperfecta and dentin dysplasia revisited, problems in classification. J Oral Pathol 1988;17:547-53.

2 Gorlin RJ, Cohen MM, Hennekam RCM. Syndromes of the head and neck, 4th ed. New York: Oxford University Press, 2001.

3 Dummett CO. Anomalies of the developing dentition. In: Pinkham JR, Caamassimo PS, McTique DJ, et al, eds. Pediatric dentistry, infancy through adolescence, 2nd ed, vol 4. Philadelphia: WB Saunders, 1994:57-68.

4 Aldred MJ, Savarirayan R, Crawford PJ. Amelogenesis imperfecta: a classification and catalogue for the 21 st century. Oral Dis 2003:9:19-23.

5 Hart PS, Michalec MD, Seow WK, Hart TC, Wright JT. Identification of the enamelin mutation (g.8344delG) mutation in a new kindred and presentation of a standardized ENAM nomenclature. Arch Oral Biol 2003;48:589-96.

6 Sundell S, Valentin J. Hereditary aspects and classification of hereditary amelogenesis imperfecta. Community Dent Oral Epidemiol 1986:14:211-16.

7 Backman B. Inherited enamel defects. Ciba Found Symp 1997;205:175-82.

8 Karrman C, Backman B, Dixon M, Holmgren G, Forsman K, 1997. Mapping of the locus for autosomal dominant amelogenesis imperfecta $(\mathrm{AlH} 2)$ to a 4-Mb YAC contig on chromosome 4q1 1-q21. Genomics 1997:39:164-70.

9 Simmer JP, Hu JC. Dental enamel formation and its impact on clinical dentistry. J Dent Educ 2001;65:896-905.

10 Online Mendelian Inheritance in Man, OMIM (TM). Johns Hopkins University, Baltimore. MIM number: $\{5 / 3 / 1999\}$ : $\{300391\}$. World wide web URL: http://www.ncbi.nlm.nih.gov/omim/.

11 Hart PS, Hart TC, Simmer JP, Wright JT. Establishment of a nomenclature for $X$-linked amelogenesis imperfecta. Arch Oral Biol 2002;47:255-60.

12 Online Mendelian Inheritance in Man, OMIM (TM). Johns Hopkins University, Baltimore. MIM number: $\{4 / 30 / 2002\}$ : $\{606585\}$. World wide web URL: http://www.ncbi.nlm.nih.gov/omim/

13 Karrman C, Backman B, Holmgren G, Forsman K. Genetic heterogeneity of autosomal dominant amelogenesis imperfecta demonstrated by its exclusion from the $\mathrm{AlH} 2$ region on human chromosome $4 \mathrm{Q}$. Arch Oral Biol 1996;41:893-900.

14 Raipar MH, Harley K, Laing C, Davies DM, Dixon MJ. Mutation of the gene encoding the enamel-specific protein, enamelin, causes autosomal-dominant amelogenesis imperfecta. Human Mol Genet 2001:10:1673-7.

15 Kida M, Ariga T, Shirakawa T, Oguchi H, Sakiyama Y. Autsomal-dominant hypoplastic form of amelogenesis imperfecta caused by an enamelin gene mutation at the exon-intron boundary. J Dent Res 2002;81:738-42.

16 Mardh K, Backman B, Holgren G, Hu J-C, Simmer J, Forsman-Semb K. A nonsense mutation in the enamelin gene causes local hypoplastic autosomal dominant amelogenesis imperfecta (AlH2). Human Mol Genet 2002;11:1069-74.

17 Hart PS, Wright JT, Savage M, Kang G, Bensen JT, Gorry MC, Hart TC Exclusion of proposed candidate genes in two families with autosomal dominant Hypocalcified amelogenesis imperfecta. Eur J Oral Sci 2003;111:326-31.

18 Hart PS, Aldred MJ, Crawford PJ, Wright NJ, Hart TC, Wright JT. Amelogenesis imperfecta phenotype-genotype correlations with two amelogenin gene mutations. Arch Oral Biol 2002;47:261-5.

19 Deutsch D, Palmon A, Fisher LW, Kolodny N, Termine JD, Young M. F. Sequencing of bovine enamelin ("Tuftelin") a novel acidic enamel protein. J Biol Chem 1991;266:16021-8.

20 Bartlett J, Simmer J, Xue J, Margolis H, Moreno E. Molecular cloning and mRNA tissue distribution of a novel matrix metalloproteinase isolated from porcine enamel organ. Gene 1996;183:123-8.

21 Simmer J, Fukae M, Tanabe T, Yamakoshi Y, Uchida T, Xhu J, Margolis H, Shimizu M, Hu C-C, Bartlett J. Purification, characterization and cloning of enamel matrix serine proteinase 1. J Dent Res 1998;7:377-86.

22 Paine ML, Krebsbach PH, Chen LS, Paine CT, Yamada Y, Deutsch D, Snead ML. Protein-to-protein interactions: criteria defining the assembly of the enamel organic matrix. J Dent Res 1998;77:496-502.

23 Hu CC, Hart TC, Dupont BR, Chen JJ, Sun X, Qian Q, Zhang CH, Wright JT, Simmer JP. Cloning human enamelin CDNA chromosomal localization and analysis of expression during tooth development. J Dent Res 2000;79:912-19.

24 Simmer JP, Hu JC. Expression, structure, and function of enamel proteinases. Connect Tissue Res 2002;43:441-9.

25 Bosch C, Athanasiou AE. Landmarks, variables and norms of various numerical cephalometric analyses - cephalometric morphological and growth data references. In: Athanasiou AE, ed. Orthodontic cephalometry. London: Mosby-Wolfe, 1995:241-86. 
26 Benson G. Tandem repeats finder: a program to analyze DNA sequences. Nucleic Acids Res 1999;27:573-80.

27 Hart TC, Zhang Y, Gorry MC, Hart PS, Cooper M, Marazita ML, Marks JM, Cortelli JR, Pallos D. A mutation in the SOS1 gene causes hereditary gingival fibromatosis type 1. Am J Hum Genet 2002;70:943-54.

28 Antonarakis SE, Group at NW. Recommendations for a nomenclature system for human gene mutations. Hum Mutat 1988;11:1-3.

29 Hobbs HH, Brown MS, Goldstein JL. Molecular genetics of the LDL receptor gene in familial hypercholesterolemia. Hum Mutat 1992;1:445-66.

30 Defesche JC, Kastelein JJ. Molecular epidemiology of familial hypercholesterolaemia. Lancet 1998;352:1643-4.

31 Termine JD, Belcourt AB, Christner PJ, Conn KM, Nylen MU. Properties of dissociatively extracted fetal tooth matrix proteins. I. Principal molecular species in developing bovine enamel. J Biol Chem 1980;255:9760-8.

32 Tanabe T, Fukae M, Shimizu M. Degradation of enamelins by proteinases found in porcine secretory enamel in vitro. Arch Oral Biol 1994:39:277-81.

33 Fukae M, Tanabe T, Murakami C, Dohi N, Uchida T, Shimizu M. Primary structure of the porcine 89-kDa enamelin. Adv Dent Res 1996;10:111-18.

34 Uchida T, Tanabe T, Fukae M, Shimizu M. Immunocytochemical and immunochemical detection of a $32 \mathrm{kDa}$ nonamelogenin and related proteins in porcine tooth germs. Arch Histol Cytol 1991;54:527-38

35 Brookes SJ, Lyngstadaas SP, Robinson C, Shore RC, Wood SR, Wood SR, Kirkham J. Enamelin compartmentalization in developing porcine enamel. Connect Tissue Res 2002;43:477-81.

36 Yamakoshi Y. Carbohydrate moieties of porcine $32 \mathrm{kDa}$ enamelin. Calcif Tissue Int 1995;56:323-30.

37 Tanabe T, Aoba T, Moreno EC, Fukae M, Shimuzu M. Properties of phosphorylated $32 \mathrm{kd}$ nonamelogenin proteins isolated from porcine secretory enamel. Calcif Tissue Int 1990;46:205-15.

38 Akita H, Fukae M, Shimoda S, Aoba T. Localization of glycosylated matrix proteins in secretory porcine enamel and their possible functional roles in enamel mineralization. Arch Oral Biol 1992;37:953-62.

39 Ravindranath RM, Moradian-Oldak J, Fincham AG. Tyrosyl motif in amelogenins binds $\mathrm{N}$-acetyl-D-glucosamine. J Biol Chem 1999;274:2464-71

40 Collier PM, Sauk JJ, Rosenbloom SJ, Yuan ZA, Gibson CW. An amelogenin gene defect associated with human X-linked amelogenesis imperfecta. Arch Oral Biol 1997;42:235-42.

41 Goodman AH, Rose JC. Dental enamel hypoplasias as indicators of nutritional status. In: Kelley MA, Larsen CS eds. Advances in dental anthropology. New York: Alan R Liss, 1991:279-93.

42 Skinner MF, Goodman AH. Anthropological uses of developmental defects of enamel. In: Saunders SR, Katzenberg MA eds. Skeletal biology of past peoples: research methods. New York: Wiley-Liss, 1992:153-74.

43 Skinner MF. Enamel hypoplasia in sympatric chimpanzee and gorilla. Hum Evolut 1986;1:289-312

44 Lukacs JR, Walimbe SR, Floyd B. Epidemiology of enamel hypoplasia in deciduous teeth: explaining variation in prevalence in western India. Am J Human Biol 2001;13:788-807.

45 Skinner MF, Tat Wai HJ. Localized enamel hypoplasia of the primary canine. ASDC J Dent Child 1986;53:197-200.

46 Skinner MF. An enigmatic hypoplastic defect of the deciduous canine. Am J Phys Anthropol 1986;69:59-69.
47 Skinner MF, Hung JT. Social and biological correlates of localized enamel hypoplasia of the human deciduous canine tooth. Am J Phys Anthropol 1989;79:159-75.

48 Skinner MF, Hadaway W, Dickie J. Effects of ethnicity and birth month on localized enamel hypoplasia of the primary canine. ASDC J Dent Child 1994;61:109-13.

49 Taji S, Hughes T, Rogers J, Townsend G. Localised enamel hypoplasia of human deciduous canines: genotype or environment? Aust Dent $J$ 2000:45:83-90

50 Lukacs JR. Enamel hypoplasia in deciduous teeth of great apes: do differences in defect prevalence imply differential levels of physiological stress? Am J Phys Anthropol 1999; 110:351-63.

51 Lukacs JR. Enamel hypoplasia in the deciduous teeth of great apes: variation in prevalence and timing of defects. Am J Phys Anthropol 2001:116:199-208.

52 Skinner MF, Newell EA. Localized hypoplasia of the primary canine in bonobos, orangutans, and gibbons. Am J Phys Anthropol 2003;120:61-72.

53 Erpenstein H, Wannenmacher E. Dental enamel hypoplasia and open bite as autosomal dominant genetic symptoms. Dtsch Zahnaertztl Z 1968;23:405.

54 Persson M, Sundell S. Facial morphology and open bite deformity in amelogenesis imperfecta. A roentgenocephalometric study. Acta Odontol Scand 1982;40:135-44.

55 Rowley R, Hill FJ, Winter GB. An investigation of the association between anterior open-bite and amelogenesis imperfecta. Am J Orthod 1982;81:229-35.

56 Wright JT. Analysis of a kindred with amelogenesis imperfecta. J Oral Pathol 1985; 14:366-74.

57 Sundell S. Hereditary amelogenesis imperfecta. An epidemiological, genetic and clinical study in a Swedish child population. Swed Dent J Suppl 1986;31:1-38

58 Backman B, Adolfsson U. Craniofacial structure related to inheritance pattern in amelogenesis imperfecta. Am J Orthod Dentofacial Orthop 1994:105:575-82.

59 Hoppenreijs TJ, Voorsmit RA, Freihofer HP. Open bite deformity in amelogenesis imperfecta. Part 1: An analysis of contributory factors and implications for treatment. J Craniomaxillofac Surg 1998;26:260-6.

60 Cartwright AR, Kula K, Wright TJ. Craniofacial features associated with amelogenesis imperfecta. J Craniofac Genet Dev Biol 1999;19:148-56.

61 Issel P. Uber Aplasie des Zsahnschmelzes inter besonderer Berucksichtiging der Prothetischen Versorginig, Zahnaerztl. Rundschau 1955;64:165.

62 Schulze C. Uber einen Fall von Hypoplasie der Hartzubstanzen bei Zahnen im Bereich des rechten Oberkiefers. Dtsch Zahnaerztl Z 1956:11:14.

63 Rao S, Witkop CJ. Inherited defects in tooth structure. Birth Defects Orig Artic Ser 1971;7:153-84.

64 Witkop CJ, Sauk JJ. Heritable Defects of Enamel. In: Stewart R, Prescott G eds. Oral facial genetics. St Louis: CV Mosby Co, 1976;151-226).

65 Todd JE. Children's dental health in England and Wales. London: HMSO 1973:56.

66 Aldred MJ, Crawford PJ. Variable expression in amelogenesis imperfecta with taurodontism. J Oral Pathol 1988;17:327-33.

67 Backman B, Lundgren T, Engstrom EU, Falk LK, Chabala JM, Levi-Setti R, Noren JG. The absence of correlations between a clinical classification and ultrastructural findings in amelogenesis imperfecta. Acta Odontol Scand 1993;51:79-89.

68 Hall JG. A clinician's plea. Nat Genet 2003:33:440-2. 